\title{
Modification of bituminous coatings to prevent stress corrosion cracking of carbon steel
}

\author{
M. A. Maleeva, V. E. Ignatenko, A. V. Shapagin, A. A. Sherbina, \\ L. B.Maksaeva, A. I. Marshakov and M. A. Petrunin \\ A. N. Frumkin Institute of Physical Chemistry and Electrochemistry, Russian Academy \\ of Sciences, Leninskii pr. 31, Moscow, 119071 Russian Federation \\ E-mail:1maksaeva@mail.ru
}

\begin{abstract}
Corrosion-mechanical tests of pipe steel specimens in the presence of organosilanes have been carried out and the effect of the latter on steel cracking resistance under slow strain in NS-4 simulated underfilm electrolyte ( $\mathrm{pH}$ 6.7), both without and with addition of sulfides, has been determined. It has been shown that organosilanes increase the crack resistance of steel, including that in sulfide-containing media. Comparative laboratory tests have been performed for adhesive strength, water resistance, and resistance to cathodic disbonding of adhesive bonds obtained by the existing technology of pipeline insulation under field conditions and using new methods for pipe surface treatment. It has been found that addition of organosilanes improves the adhesive characteristics of a bitumen-polymeric coating on pipe steel.
\end{abstract}

Key words: organosilanes, adhesion, stress corrosion cracking, corrosion inhibitors.

Received: June 9, 2015.

doi: $\underline{10.17675 / 2305-6894-2015-4-3-226-234}$

\section{Introduction}

Though there is some progress in reducing the risk of accidents caused by stress corrosion cracking (SCC) in major gas pipeline transport objects [1], the problem of preventing the $\mathrm{SCC}$ of pipeline outer walls remains a pressing issue.

In view of this, in addition to the measures aimed at improving the quality of repair operations, creation of anticorrosion protective coatings of a new type appears to be a very promising approach. These coatings should not only insulate the metal from exposure to the corrosive environment, but also aid in preventing the repeated development of stress corrosion defects.

Corrosion inhibitors (CIs) are compounds that can considerably decrease the corrosion rate of metals, up to complete corrosion prevention. The efficiency of CIs has been proved by their long-term usage in various industries involving operation of metal structures, constructions and devices [2]. The use of CIs in pipeline transport generally aims at decreasing the rate of inside corrosion of field pipelines. To combat outside corrosion, cathodic protection can be used simultaneously with anticorrosion polymeric coatings that are efficient against general corrosion but nearly do not prevent the 
development of local corrosion processes, SCC in particular. In view of this, development of an efficient SCC inhibitor is a task of current interest. It is known that SCC in major and field gas pipelines occurs by the local anodic dissolution mechanism [3]. Therefore, the CI should be of passivating type and should form nanosized passivating surface layers that suppress electrochemical processes on pipe steel surface. Since the most technologically acceptable method of inhibitor delivery to the metal surface involves introducing a CI into a polymeric coating, more specifically into the primer composition, the CI must meet a number of requirements, the main one being the preservation of the standard adhesion characteristics of the protective coating, namely, adhesion and water resistance [4]. Furthermore, in case the integrity of the insulating coating is violated and the pipe metal contacts the ground (underfilm) electrolyte, it is necessary to ensure that the CI would dissolve in the underfilm solution in an amount sufficient for inhibition, which is achieved by a high mobility of the inhibitor in the polymer bulk and the inhibitor would evolve into solution in case of coating delamination.

Organosilanes $\left(\mathrm{R}_{n} \mathrm{Si}\left(\mathrm{OC}_{2} \mathrm{H}_{5}\right)_{4-n}\right)$ are ecologically safe compounds that are adsorbed on metal surfaces to form self-organizing siloxane surface nanolayers [5]. On the one hand, this results in strong and hydrolytically stable $\mathrm{Me}-\mathrm{O}-\mathrm{Si}$ bonds with the hydroxylated metal surface. On the other hand, varying the chemical nature of organic radical $\mathrm{R}$ makes it possible to provide a high affinity of the nanolayer to a broad range of polymeric and paint materials [6]. It has been shown [7] that silanes can improve the corrosion resistance of metals. With this in mind, the purpose of this study was to develop a method for modifying a polymeric coating with organosilicon compounds that would hinder the SCC of pipe steel while maintaining high adhesion and water resistance of the insulation coating.

\section{Experimental details}

Specimens were made of a pipe steel corresponding to X70 strength grade. Vinylsilane (VSil) and aminosilane (ASil) were used as the organosilicon corrosion inhibitors. The bitumen-polymeric coating used in the study consisted of "Dekom-Gaz" heat-resistant bitumen-polymeric primer, "Dekom-RAM" heat-resistant reinforced putty material, and "Dekom-Kor" polymer band [8]. The CI was introduced into the bulk of the "Dekom-Gaz" bitumen-polymeric primer in an amount of 1 mass $\%$.

The following test solutions were used:

- a mixture of borate buffer $\left(0.4 \mathrm{M} \mathrm{H}_{3} \mathrm{BO}_{3}+0.1 \mathrm{M} \mathrm{Na}_{2} \mathrm{~B}_{4} \mathrm{O}_{7}\right)(\mathrm{pH}$ 6.7) and NS-4 electrolyte whose ionic composition matches the liquid found under delaminated coatings of underground pipe lines in areas subject to SCC [9].

- an aqueous extract of the CI from the "Dekom-Gaz" primer. The aqueous extract was prepared from the primer containing the CI. The primer was dried in air, pulverized, and placed in a solution of buffered ground electrolyte. The extraction time was 50 days. 
Corrosion-mechanical tests were performed by slow strain rate testing (SSRT) [10] using cylindrical specimens according to [11]. The design of the specimens is shown in Figure 1 and their dimensions are listed in Table 1. The specimens were mechanically treated under conditions that excluded overheating and cold-work hardening in the working section. The roughness $(\mathrm{Ra})$ of the specimen working surface was $1.25 \mu \mathrm{m}$.

The specimens were fastened in the grips of a HYBER AB tensile machine and immersed, together with the grips, into the test solution. The specimens were slowly strained by means of a reducing gear at a constant speed ranging from $2 \cdot 10^{-6}$ to $1 \cdot 10^{-4} \mathrm{~mm} / \mathrm{s}$. The test was finished upon specimen breakdown and the time to breakdown was recorded. The broken specimens were washed with distilled water, dried in air and placed in a desiccator. After a test, the time to breakdown and the presence of cracks on the working part of the specimen were recorded. In addition, the specimen contraction ratios were measured. The contraction ratio after specimen breakdown is calculated using formula (1):

$$
R A=S_{0}^{-1} \cdot\left(S_{0}-S_{k}\right) \cdot 100 \%,
$$

where: $S_{0}$ is the starting cross-section area of the specimen, $\mathrm{mm}^{2} ; S_{k}$ is the cross-section area of the specimen after breakdown, $\mathrm{mm}^{2}$.

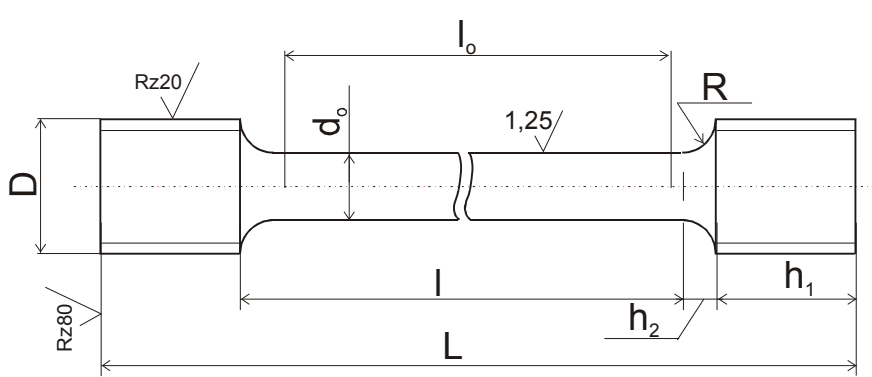

Figure 1. Design of the specimen for SSRT tests.

Table 1. Dimensions of specimens for SSRT tests, mm.

\begin{tabular}{cccccccc}
\hline $\boldsymbol{d}_{\mathbf{0}}$ & $\boldsymbol{I}_{\mathbf{0}}=\mathbf{1 0} \boldsymbol{d}_{\mathbf{0}}$ & $\boldsymbol{I}$ & $\boldsymbol{D}$ & $\boldsymbol{h}_{\mathbf{1}}$ & $\boldsymbol{h}_{\mathbf{2}}$ & $\boldsymbol{R}$ & $\boldsymbol{L}$ \\
\hline 2.5 & 25 & $I_{0}+(0.5-2) d_{0}$ & M 5 & 10 & 2.5 & 2.5 & $I+2\left(h_{1}+h_{2}\right)$ \\
\hline
\end{tabular}

The adsorption of silanes from the aqueous extract was studied by Fourier IR spectroscopy after exposure of the primer inhibited with silanes to a solution for 50 days. To do so, an X70 pipe steel specimen with dimensions of $25 \times 15 \times 2 \mathrm{~mm}$ was placed in the aqueous extract solution and kept there for $10 \mathrm{~min}$. The specimen was dried in air and its reflection IR spectrum was recorded. Reflection IR spectra were obtained using a Nicolet iN10 FT-IR Microscope (Thermo Fisher Scientific Inc., USA) in the range of 600$4000 \mathrm{~cm}^{-1}$, resolution: $4 \mathrm{~cm}^{-1}$, number of scans: 400 . A mirror reflection unit with an incidence angle of $80^{\circ}$ was used.

The adhesion of "Dekom" polymeric formulation consisting of "Dekom-Gaz" primer and "Dekom-RAM" material was performed by tearing the coating off the metal at $90^{\circ}$ 
angle according to (12) by means of a Zwick/Roell Z 010 tearing machine. Steel plates with dimensions of $100 \times 150 \times 3 \mathrm{~mm}$ were used. Their working sections were coated with "Dekom-Gaz" primer containing a CI, along with a band of "Dekom-RAM" material and "Dekom-Kor" band attached (Figure 2). The specimens for the tests were prepared according to (5). The coverage rate of the primer was $300 \mathrm{~g} / \mathrm{m}^{2}$. The coating thickness was determined by an EASY-CHECK FN thickness gage. The coating thickness was $4.81 \pm 0.05 \mathrm{~mm}$.

The adhesive strength in $\mathrm{N} / \mathrm{cm}$ of the width was calculated using the formula:

$$
A=F / B,
$$

where $\mathrm{F}$ is the delamination force in the monitored zone (in $\mathrm{N}$ ) and $\mathrm{B}$ is the delamination band width (in $\mathrm{cm}$ ).

The adhesion water resistance was estimated by measuring adhesion, which was performed by tearing the coating off at $90^{\circ}$ angle after keeping the specimens in water for $1000 \mathrm{~h}$ at $20 \pm 1^{\circ} \mathrm{C}$.
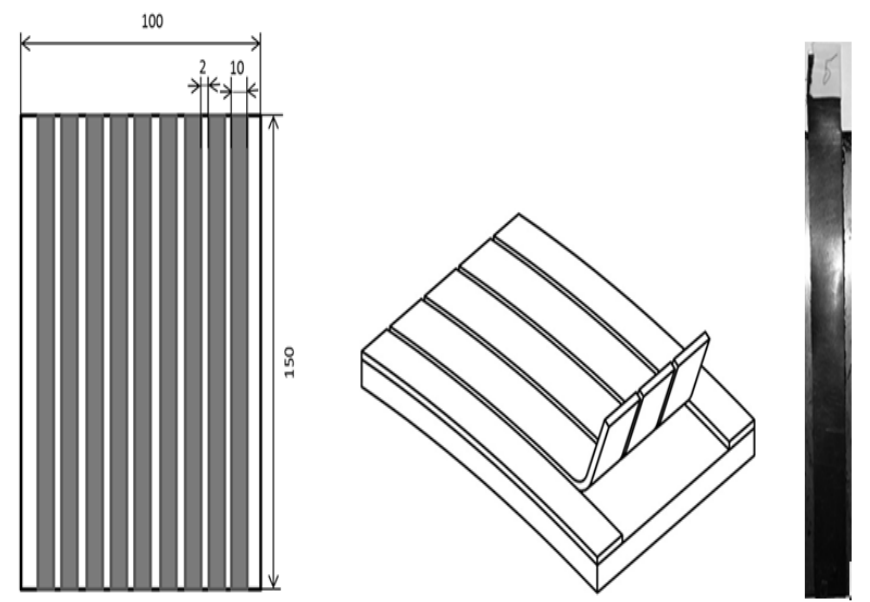

Figure 2. Test specimen for measurement of "Dekom" coating adhesion by the delamination method.

\section{Results and discussion}

To determine the effect of organosilanes on the susceptibility of pipe steel to SCC by SSRT method, we performed corrosion-mechanical tests of X70 grade pipe steel. Figure 3 shows the results of the tests.

One can see from Figure 3 that addition of 1\% VSil decreases the susceptibility of pipe steel to SCC, both in the background electrolyte and in the presence of an SCC activator (Figure $3 a$ ). Addition of the aminosilane (ASil) to the background solution does not decrease the steel susceptibility to SCC but even slightly increases it. However, in the sulfide-containing solution that accelerated the crack formation processes, we observed SCC inhibition upon addition of $1 \%$ aminosilane to the solution. Thus, it can be expected that the presence of organosilanes in the underfilm electrolyte upon coating delamination 
from the metal during operation of an underground structure would decrease the origination and development of SCC in the steel structure.

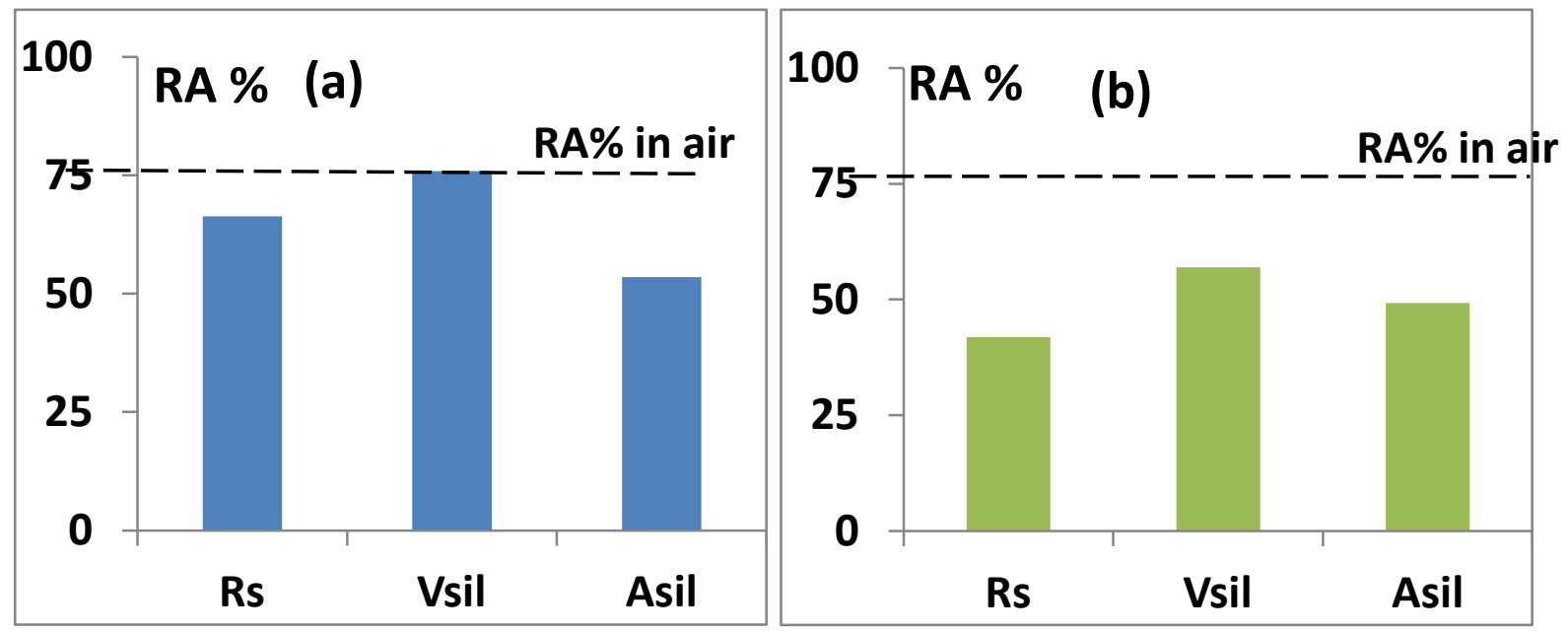

Figure 3. Plot of contraction ratio of pipe steel specimen during SSRT tests in background solution NS-4 + borate buffer, $\mathrm{pH} 6.7$ (BS) (a) and in the background solution containing $10 \mathrm{mM}$ sodium sulfide as an SCC activator $(b)$.

In order to ensure efficient inhibition of steel structure SCC, a method of applying the inhibitors has to be developed. As such a method, it was suggested to introduce organosilanes into the bulk of the bitumen-polymeric primer. However, at least two main conditions have to be met in this application method. First, the compound inhibiting SCC should be sufficiently mobile and should evolve into the underfilm electrolyte in case of delamination of the polymeric coating from the metal, thus ensuring inhibition of the origination and growth of a corrosion crack. Second, incorporation of inhibiting formulations into a polymeric coating should, at least, not worsen the adhesion characteristics of the coating, and optimally, it should increase the strength and stability of the metal-polymer adhesive junction.

To determine the ability of the inhibitor to evolve from the primer bulk to the underfilm electrolyte and be adsorbed on a metal surface, we performed a Fourier IR spectroscopic study of a metal surface exposed for 10 minutes in an aqueous extract from the polymeric coating with vinylsilane introduced into the coating bulk. The coating was kept for 50 days in distilled water.

Figure 4 presents a Fourier IR spectrum of steel surfaces treated with an 1\% VSil aqueous solution (Figure 4, curve 1) or with a aqueous extract from inhibited "DekomGaz" primer (Figure 4, curve 2). Coinciding bands on both curves can be seen in the figure, which indicate that VSil evolves from the bulk of the polymeric coating into solution. The IR spectrum of the aqueous extract from the inhibited primer contains a number of bands attributed to the vinylsiloxane layer formed upon hydrolysis and polycondensation of VS molecules on the surface. The intense bands around $1030 \mathrm{~cm}^{-1}$ and $1000 \mathrm{~cm}^{-1}$ are in the region of vibrations of the Si-O-Si bond [13], while the band at $905 \mathrm{~cm}^{-1}$ corresponds to 
the vibrations of the bridging oxygen atom bonds in the $\mathrm{Si}-\mathrm{O}-\mathrm{Si}$ moiety. The bands at 1411 and $1600 \mathrm{~cm}^{-1}$ are located in the regions close to the vibrations of the $-\mathrm{CH}=\mathrm{CH}_{2}$ double bond, while that band at $2950 \mathrm{~cm}^{-1}$ is close to the region of vibrations of $\mathrm{CH}_{2}$ bonds in the vinyl group [13]. The band at $770 \mathrm{~cm}^{-1}$ corresponds to the vibrations of siliconcarbon bonds [14]. The broad low-intensity band near $3370 \mathrm{~cm}^{-1}$ is in the region of vibrations of the $\mathrm{OH}$ group in the $\mathrm{Si}-\mathrm{OH}$ moiety [15]. Furthermore, a band around $950 \mathrm{~cm}^{-1}$ was detected in the spectrum. It was attributed to vibrations of the $-\mathrm{Fe}-\mathrm{O}-\mathrm{Si}-$ surface groups [16].

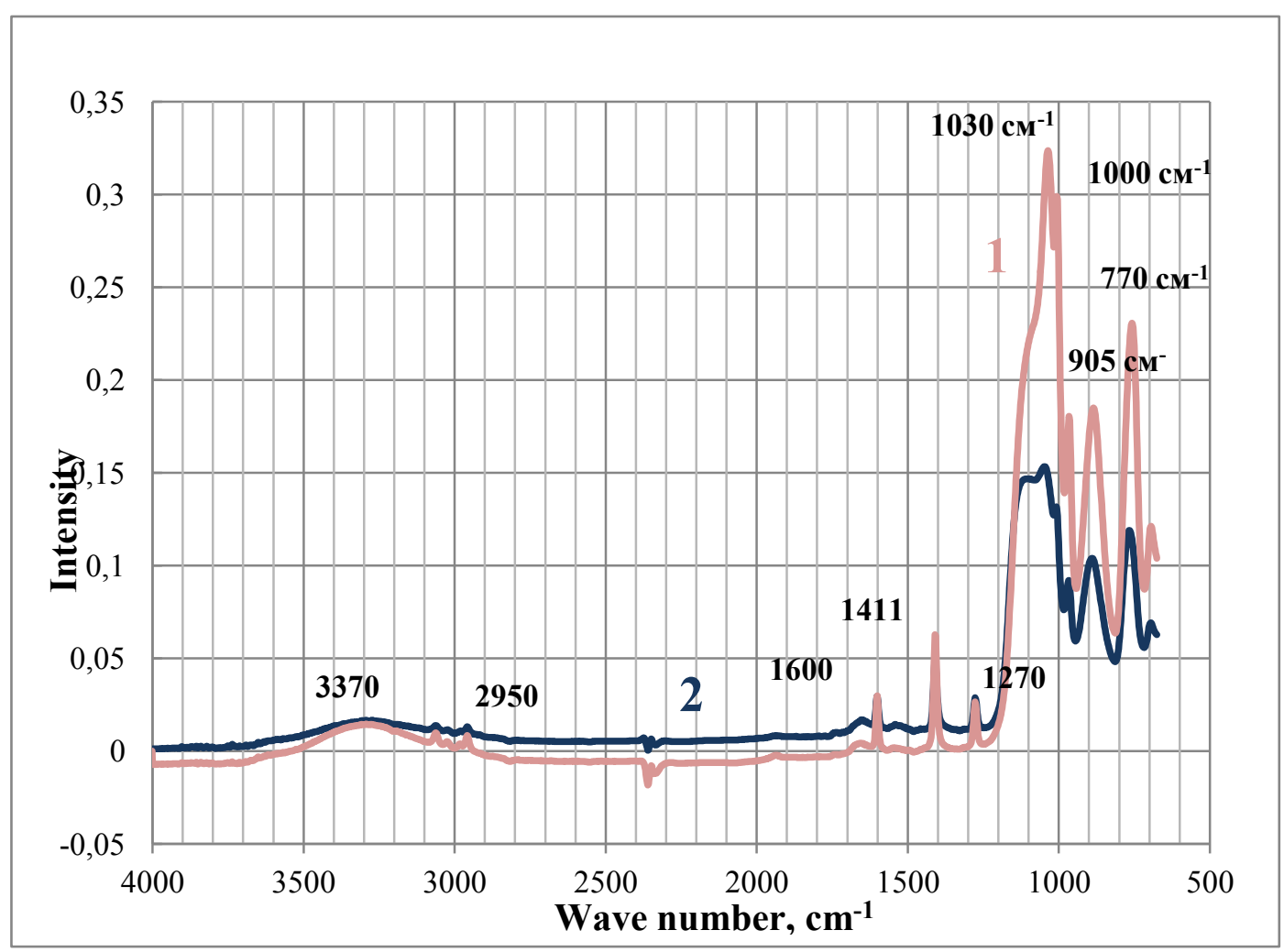

Figure 4. Fourier IR spectrum of steel surface treated with: 1 - 1\% aqueous VSil solution; 2 aqueous extract from inhibited "Dekom-Gaz" primer obtained in 50 days.

Analysis of the spectra allows us to determine the nature of the chemical processes occurring on steel surface upon VS adsorption from the underfilm electrolyte. In fact, hydrolysis of vinylsilane molecules to give a silanol is the first stage of the process, since no bands corresponding to the vibrations of $\mathrm{Si}-\mathrm{O}-\mathrm{C}$ groups were found in the spectrum, but bands corresponding to $\mathrm{Si}-\mathrm{OH}$ groups were observed. This indicates that the surface contains no non-hydrolyzed VS molecules. The appearance of the band around $950 \mathrm{~cm}^{-1}$ corresponding to the $-\mathrm{Fe}-\mathrm{O}-\mathrm{Si}$ vibrations indicates that chemical interaction exists between VSil molecules and the hydroxyl groups on the metal surface. Subsequently, the adjacent adsorbed molecules undergo polycondensation to give bridging $\mathrm{Si}-\mathrm{O}-\mathrm{Si}$ bonds resistant to hydrolysis, as indicated by the presence of bands around $1030 \mathrm{~cm}^{-1}, 1000 \mathrm{~cm}^{-1}$, and $905 \mathrm{~cm}^{-1}$. 
Thus, the IR study has shown that VSil can not only evolve from the coating into the underfilm electrolyte, but also be adsorbed on the pipe steel surface to form strong surface bonds.

Since a high adhesive strength is the main protective characteristics of pipeline insulation materials, we studied the effect of CI on the adhesion properties of the bitumen coating. Since organosilanes are known adhesion promoters that improve the adhesion characteristics of a wide range polymeric coatings on inorganic substrates [7], it could be expected that incorporation of vinyl- and amino-containing silanes into a bitumenpolymeric coating would have no adverse effect on the coating adhesive properties. We studied the effect of organosilanes on the adhesion and adhesion water resistance of a bitumen-polymeric coating.

The adhesive strength values for "Dekom" bitumen-polymeric coating are shown in Figure $5 a$ and its adhesion water resistance values are shown in Figure $5 b$.
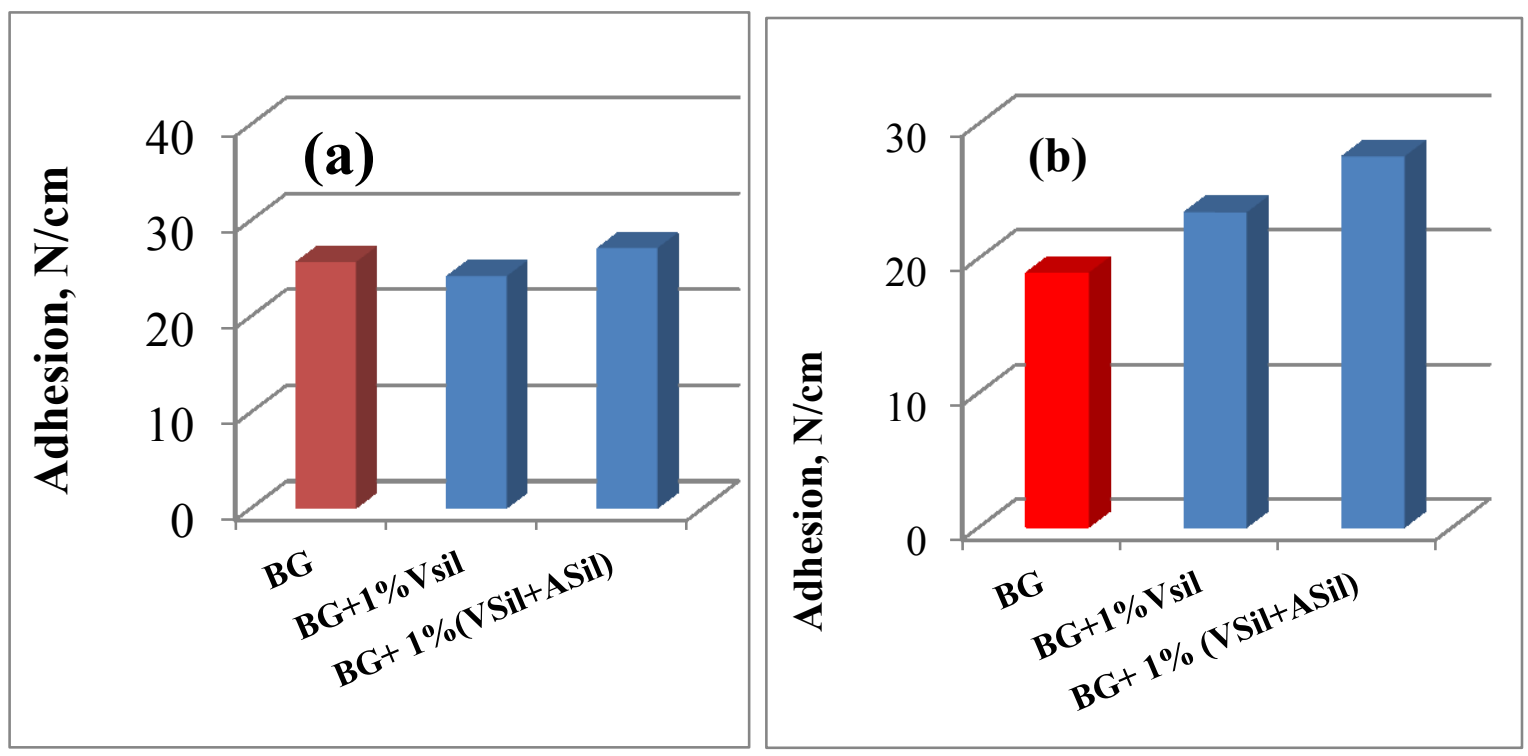

Figure 5. Adhesive strength during tear-off (at $90^{\circ}$ angle) of "Dekom-Gaz" bitumenpolymeric primer containing no additives $(\mathrm{BG})$ and containing organosilanes $(a)$ and after exposure of the metal-polymer adhesive junction in water for $1000 \mathrm{~h}, t=20^{\circ} \mathrm{C}(b)$.

One can see from Figure 5 that incorporation of vinylsilane into the coating does not decrease the dry adhesion but increases the water resistance of the bitumen-polymeric coating. The use of a mixture of vinyl- and aminosilanes can considerably improve the adhesive properties of a bitumen-polymeric coating on pipe steel. It will also hinder the metal SCC, since it is known that SCC occurs under delaminated coatings. Incorporation of a CI into a coating will not only inhibit SCC development after coating delamination but can also prolong the failure-free operation of an isolation coating, which would additionally increase the overall operation life of the structure. 
Thus, the results of combined testing have shown that incorporation of organosilanes into a polymeric coating can decrease the probability of SCC origination and decrease its development on underground steel structures.

\section{Conclusion}

1. Corrosion-mechanical tests of pipe steel specimens in the presence of organosilanes have been carried out and the effect of the latter on steel cracking resistance under slow strain in NS-4 simulated underfilm electrolyte ( $\mathrm{pH}$ 6.7), both without and with addition of sulfides, have been determined. It has been shown that organosilanes increase the crack resistance of steel, including that in sulfide-containing media.

2. Comparative laboratory tests have been performed for adhesive strength, water resistance, and resistance to cathodic disbonding of adhesive bonds obtained by the existing technology of pipeline insulation under field conditions and using new methods for pipe surface treatment. It has been found that addition of organosilanes improves the adhesive characteristics of a bitumen-polymeric coating on pipe steel.

3. Based on the combined laboratory tests, vinylsilane has been recommended as an additive for benchmark and pilot testing.

\section{References}

1. The annual report on the activities of the Federal Service for Ecological, Technological and Nuclear Supervision in 2013, Moscow, 2014 (in Russian), http://www.gosnadzor.ru/public/annual_reports/\%D0\%9E $\%$ D1\%82\%D1\%87\%D0\%B5 $\%$ D1\%82\%202013.pdf

2. H. H. Uhlig and R. W. Revie, Corrosion and Corrosion Control, 3rd edn., WileyInterscience, New York, 1985.

3. A. I. Marshakov, V. E. Ignatenko, R. I. Bogdanov and A. B. Arabey, Corros. Sci., 2014, 83, 209.

4. GOST R 51164-98, Steel pipe mains. General requirements for corrosion protection, Moscow, 1999, 46 pp. (in Russian).

5. A. N. Bruce, D. Lieber, I. Hua and J. A. Howarter, J. Colloid Interface Sci., 2014, 419, 73.

6. E. P. Pluddemann, Silane Coupling Agents, Plenum Press, New York, 1982.

7. M. A. Petrunin, L. B. Maksaeva, T. A. Yurasova, E. V. Terekhova, M. A. Maleeva, A. A. Shcherbina, V. A. Kotenev, E. N. Kablov and A. Yu. Tsivadze, Prot. Metals Phys. Chem. Surf., 2014, 50, 784.

8. TU (RF Technical specification) 5774-015-32989231-2013, Termoresistant rollreinforced mastic material "Dekom-Ram" (in Russian). http://www.delan.su/products/dekomram.html

9. R. N. Parkins, W. K. Blanchard and B. S. Delanty, Corrosion, 1994, 50, 394. 
10. V. E. Ignatenko, Yu. I. Kuznetsov, A. B. Arabei, R. V. Igoshin, R. I. Bogdanov and A. I. Marshakov, Int. J. Corr. Scale Inhib., 2013, 2, no. 4, 318. doi: 10.17675/2305$\underline{6894-2013-2-4-318-336}$

11. ISO 6892-1:2009, Metallic materials -- Tensile testing -- Part 1: Method of test at room temperature // GOST 1497 - 84, Metals. Methods of tension testing, Moscow, 2008. 22 pp. (in Russian).

12. ISO 813:1997, Rubber, vulcanized or thermoplastic - Determination of adhesion to a rigid substrate - 90 degree peel method // GOST 411-77, Rubber and glue. Methods for determination of metal bond strength at separation, Moscow, 2002, 9 pp. (in Russian).

13. D. O. Flamini, M. Trueba and S.P. Trasatti, Progr. Org. Coat., 2012, 74, 302.

14. H. Ishida and L. Koenig, J. Colloid and Interface Sci., 1978, 64, 555.

15. A. Franquet and H. Terryn, Thin Solid Films, 2003, 441, 76.

16. C. Chaneac, E. Tronc and J. P. Jolivet, J. Mater. Chem., 1996, 6, 1905. 